\title{
La biblioteca escolar y el perfil del bibliotecario escolar
}

The school library and the profile of the postpandemic school librarian

\section{Noemí Conforti}

Universidad Nacional de Mar del Plata. Facultad de Humanidades.

Departamento de Ciencia de la Información, Argentina

noemiconforti@yahoo.com.ar

(D) http://orcid.org/0000-0002-5056-5507

\section{Claudia Marisol Palacios}

Universidad Nacional de Mar del Plata. Facultad de Humanidades.

Departamento de Ciencia de la Información, Argentina

claumarisol@hotmail.com

http://orcid.org/0000-0002-0781-1792

\section{María Segunda Varela}

Universidad Nacional de Mar del Plata. Facultad de Humanidades.

Departamento de Ciencia de la Información, Argentina

mariasegundavarela@hotmail.com.ar

iD http://orcid.org/0000-0003-4230-50136

\section{Resumen:}

El concepto de biblioteca escolar requiere una nueva mirada y profesionalización en competencias por parte de los bibliotecarios escolares sobre el uso e impacto de las herramientas digitales en los procesos de enseñanza y aprendizaje para poder impulsar programaciones transversales.

En este trabajo se invita a la reflexión para generar un debate acerca de las bibliotecas escolares y el rol de los profesionales en el transitar hacia una nueva normalidad pospandemia.

Palabras ClaVe: Biblioteca escolar, Bibliotecario escolar, Pospandemia, Competencias, Pedagogía digital..

KeYwords: School libraries, School librarian, Post pandemic, Professional skills, Digital pedagogy

El bibliotecario se convierte en un "filtro colaborativo" para sus usuarios, un curador de contenidos que conoce sus necesidades e intereses. Si bien la expresión se vincula con el mercado, siendo una técnica utilizada por los sistemas de recomendación creada para solventar los problemas derivados de la sobreinformación, hoy se asocia con el rol que en la actualidad se requiere del profesional. Ser experto en información multiformato, que proporciona un acceso equitativo a la información, que forma en el uso de los variados dispositivos conectados a internet y en el aprovechamiento del contenido disponible en línea, mediador en el desarrollo de las habilidades necesarias para optimizar las oportunidades educativas, económicas y sociales que se asocian con la tecnología.

Toda biblioteca escolar (BE) que pretenda ser un servicio de calidad, además de disponer de una colección de documentos bien seleccionados y catalogados, debe generar una serie de productos y servicios propios de 
carácter formativo y participativo, orientados directamente a los distintos usuarios, que deben dar pie a la colaboración, tanto en su creación como en su diseño.

Actualmente, ser especialista en la gestión de información nos coloca un paso por delante para abordar los retos de la sociedad. El desafío para los profesionales de la información, ante el impacto de lo digital en nuestras vidas, no es tanto preservar el pasado como crear nuestro futuro.

Paulo Freire (1997, p. 47) afirmaba en los años sesenta: "enseñar no es transferir conocimiento, sino crear las posibilidades para su producción o su construcción”. Es en este contexto donde el rol del bibliotecario escolar como mediador en el desarrollo del aprendizaje se enmarca, por su misión pedagógica, en el fortalecimiento del conocimiento adquirido y su función transversal en la institución educativa.

En la sociedad del conocimiento asistimos a la necesidad de plantear una combinación de alfabetizaciones, ya que ninguna por sí sola es suficiente para capacitar a los individuos ante las abundantes y diversas maneras en que la información se manifiesta y los mensajes se transmiten. La tecnología no es simplemente una posibilidad técnica, sino que supone prácticas sociales, dinámicas políticas y sensibilidades que son las que determinan los sentidos y modos de uso (Dussel y Quevedo, 2010).

El concepto de BE a nuestro criterio se ha ampliado, no alcanza la mirada de centro de recursos para el aprendizaje, hoy es necesario visualizarlo como:

- Un espacio de igualdad de oportunidades. Tal como lo expresa la cita en el Manifiesto de IFLA/ UNESCO (1999) donde una de las funciones es "ofrecer oportunidades" de crear y utilizar la información, entre otras. Cuando se habla de igualdad, se debe analizar que esas oportunidades son para "todos" los ciudadanos.

- Un espacio como tercer lugar. "Los terceros lugares son espacios necesarios para el desarrollo de la sociedad, a los que la gente acude por el puro placer de socializar” (Gallo-León, 2019, p. 2). ¿Por qué la BE debe estar ajena a este concepto? Música en sus espacios, juegos en línea, amueblamientos fuera de los tradicionales, son algunas de las propuestas de este nuevo concepto, en donde los usuarios se apropien de un lugar donde puedan relajarse y socializar.

- Un espacio para innovar, en donde es necesario ver a las tecnologías de la información y comunicación, representadas en el ideario colectivo por computadoras, tablets y celulares, como elementos conciliables con los libros. Se debe profundizar en el hecho de que "el usuario se acerca a buscar" y así se ampliará la perspectiva y se visualizará un nuevo panorama.

Se puede finalmente decir que la BE debe ser un referente estable, consistente, con claro reconocimiento, poniendo a disposición servicios con valor y sustentados de una infraestructura de recursos de información y humanos altamente profesionales abiertos a la comunidad con responsabilidad social.

Es en este sentido que consideramos necesario prepararnos y transformarnos en verdaderos formadores, poniendo énfasis en la importancia de alfabetizar como camino para una sociedad del conocimiento más justa, democrática e inclusiva. Efectivamente, la innovación no es una simple mejora, sino una transformación, una ruptura con los esquemas y la cultura vigentes en las instituciones. En este contexto, las bibliotecas y los bibliotecarios deben ser ágiles, creativos, centrarse en los usuarios y sus necesidades, y sobre todo, implicarse en el aprendizaje y en el proceso de innovación que ha de someterse a una revisión crítica constante.

Coincidimos con Buckingham (2007) en que la innovación pedagógica no debe confundirse con más computadoras en el aula puestas a resolver los problemas de la enseñanza. Esa confianza en el poder de las tecnologías para transformar la educación, "omite la referencia a aspectos críticos como las débiles articulaciones curriculares, los usos banales de las TIC, los usos diferenciados según el capital social y cultural involucrado, los problemas de la infraestructura y la conectividad" (Citado en Grasso, Pagola, Zanotti, 2017, p. 95). 
Anhelamos que la mirada de la BE deje de ser la de un aula llena de libros, sino el lugar o el espacio idóneo desde el cual se impulsan programaciones transversales de enseñanza y aprendizaje, que involucren a las distintas áreas para aprender técnicas de acceso, valoración, uso y producción de información, siendo los bibliotecarios realmente proactivos, promoviendo metodologías que permiten adquirir habilidades y destrezas en el uso.

Para ello, nos resulta necesario trabajar en la formación docente y en la formulación de nuevos repertorios de buenas prácticas pedagógicas que consientan hacer usos más complejos y significativos de los medios digitales. También analizar la formación académica de los bibliotecarios, trabajando en los planes de estudio de las carreras, los programas de las asignaturas y los objetivos de cada área, con relación a las multialfabetizaciones, la pedagogía y la cultura digital.

Lograr que la pedagogía gobierne la tecnología debería ser el desafío central de la política pública, en donde las BE asuman su papel protagónico, un lugar único de cualquier institución educativa que aspire a impulsar la educación como fuerza transformadora en sociedades jaqueadas por la pobreza y la desigualdad (OEI, 2010), a las que se suma ahora la incertidumbre económica y financiera.

La pedagogía de la era digital es una pedagogía en continua construcción que busca una reflexión sopesada sobre el uso y el impacto de las herramientas digitales en los procesos de enseñanza y aprendizaje, acercándose a las mismas desde una perspectiva pedagógica crítica sin limitar las reflexiones al uso de las tecnologías digitales para la enseñanza digital.

Una biblioteca visible y adaptada a los desafíos cambiantes en el siglo XXI, post pandemia, debería ser un modelo de unidad de información en donde se pueda y deba incluir plenamente la labor docente haciendo uso de la misma como un espacio de igualdad de oportunidades, como un tercer lugar, pero sobre todo como un espacio para innovar en donde su concepto se defina y redefina constantemente como un lugar democrático, cultural, de cambio social y participación ciudadana. Tal como expresara Guillermo Castán Lanaspa (2008, p. 77) "considerar a la biblioteca como el espacio de la posibilidad".

La pandemia mundial COVID-19 ha cambiado las actividades educativas, económicas, sociales y culturales. Bibliotecarios y bibliotecas de todo tipo en el mundo están tomando decisiones difíciles sobre qué servicios ofrecer y cómo hacerlo, intentando centrar sus funciones hacia herramientas, plataformas, recursos y servicios digitales, reuniendo todos los esfuerzos en la actividad sanitaria.

Las BE también, en este periodo de incertidumbre, están involucradas en la búsqueda de alternativas, prácticas y actividades de aprendizaje por medio de espacios virtuales, que favorezcan la participación, el debate, como también para pasar el rato, relajarse y crear. Es el momento de establecer lazos y redes con otras instituciones, individuos y comunidades para cubrir las necesidades de todos los ciudadanos.

Desde esta mirada y ante la necesidad del cumplimiento de su misión y adecuarse a estos tiempos, la conceptualización debería hacer hincapié en una BE no solo como centro de recursos para el aprendizaje con una mirada multimedia, activa, estimulante, formativa, participativa, actualizada, recreativa, preparadora e incluyente de todos los avances tecnológicos en materia de almacenamiento y transmisión de información, sino también en una institución generadora de situaciones de aprendizajes, activadora del pensamiento, dinamizadora de ideas y proyectos, desarrollando en cada usuario el aprender a ser, el saber ser y el aprender a aprender.

Los bibliotecarios tienen competencias desarrolladas, pero faltan otras. Fernando Ariel López, actual Director de la Biblioteca Nacional de Maestros, en una charla manifestaba al respecto que debemos seguir profesionalizándonos con otros, para otros y con nosotros. ${ }^{1}$ Esta expresión nos conduce a una posible línea de investigación acerca de las capacitaciones, los cursos, los talleres, las carreras, etc., que han realizado/ cursado los profesionales a cargo de las BE. Además de relevar cuáles han sido las ofertas y posibilidades de actualización y capacitación específicas vinculadas por ejemplo a conocimientos técnicos y procesamiento de la información, la gestión de bibliotecas, el desarrollo de colecciones, la alfabetización informacional, las multialfabetizaciones, etc. 
Por último, son variados los trabajos vinculados con protocolos de preparación para la reapertura de las bibliotecas a nivel mundial, otros con el patrimonio documental, el derecho de autor, el acceso a las colecciones y servicios en forma remota, entre otros, pero en este trabajo solo pretendemos reflexionar acerca del rol de los profesionales y de las BE para cuando todo esto pase.

\section{ReFERENCIAS}

Buckingham, D. (2007). Crecer en la era de los medios electrónicos. Madrid: Morata.

Castán Lanaspa, G. (2008). La biblioteca escolar y la igualación de oportunidades. En E. Bonilla; D. Goldin y R. Salabarría, (Coords.). Bibliotecas y escuelas: retos y posibilidades en la sociedad del conocimiento (pp. 77-107). Barcelona: Océano.

Dussel, I. y Quevedo, L. A. (2010). VI Foro Latinoamericano de Educación. Educación y nuevas tecnologias: los desafios pedagógicos ante el mundo digital. Buenos Aires: Fundación Santillana. Recuperado de https://www.unsam.edu .ar/escuelas/humanidades/actividades/latapi/docs/Dussel-Quevedo.pdf

Freire, P. (1997). Pedagogía de la autonomía: saberes necesarios para la práctica educativa. México DF: Siglo XXI.

Gallo-León, J. P. (2019) Crítica y ratificación del modelo del tercer lugar para las bibliotecas. Anuario ThinkEPI, 13, 1-9. doi: https://10.3145/thinkepi.2019.e13b01

Grasso, M.; Pagola, L. y Zanotti, A. (2017). Políticas de inclusión digital en Argentina. Usos y apropiaciones dentro y fuera de la escuela. A. Pixel-Bit. Revista de medios y educación, 50, 95-107. Recuperado de https://www.redal yc.org/articulo.oa?id=368/36849882006

IFLA / UNESCO. (1999). School library manifesto. Recuperado de https://www.ifla.org/ES/publications/ifla-unesc o-school-library-manifesto-1999

OEI. (2010). Metas educativas 2021: la educación que queremos para la generación de los bicentenarios. Madrid: OEI. Recuperado de http://www.oei.es/historico/metas2021/libro.htm

\section{Notas}

1 Palabras pronunciadas en el ciclo Charlas abiertas sobre Unidades de Información organizada por la asignatura Introducción a la Información y Comunicación del Departamento Ciencia de la Información de la Facultad de Humanidades de la Universidad Nacional de Mar del Plata, realizada el 16 de junio del 2020. 